\title{
debates
}

\section{Humanização na saúde: um novo modismo?}

\author{
The humanization of healthcare: a new fad? \\ Humanización en la salud: ¿Un nuevo modismo?
}

8

\author{
Regina Benevides ${ }^{1}$ \\ Eduardo Passos ${ }^{2}$
}

Acompanhamos o debate em torno do tema da humanização no campo da saúde, impulsionado recentemente pela construção da Política Nacional de Humanização da atenção e da gestão na saúde (PNH), com a qual estivemos implicados em 2003 e 2004 na posição de integrantes da equipe da Secretaria Executiva (SE) do Ministério da Saúde (MS).

Ainda que timidamente, este tema se anuncia desde a XI Conferência Nacional de Saúde, CNS (2000), que tinha como título "Acesso, qualidade e humanização na atenção à saúde com controle social", procurando interferir nas agendas das políticas públicas de saúde. De 2000 a 2002, o Programa Nacional de Humanização da Atenção Hospitalar (PNHAH) iniciou ações em hospitais com o intuito de criar comitês de humanização voltados para a melhoria na qualidade da atenção ao usuário e, mais tarde, ao trabalhador. Tais iniciativas encontravam um cenário ambíguo em que a humanização era reivindicada pelos usuários e alguns trabalhadores e, no mínimo, secundarizada (quando não banalizada) pela maioria dos gestores e dos profissionais. Os discursos apontavam para a urgência de se encontrar outras respostas à crise da saúde, identificada por muitos como falência do modelo SUS. A fala era de esgotamento. De fato, cada posição neste debate se sustenta com as suas razões. Por um lado, os usuários por reivindicarem o que é de direito: atenção com acolhimento e de modo resolutivo; os profissionais, por lutarem por melhores condições de trabalho. Por outro lado, os críticos às propostas humanizantes no campo da saúde denunciavam que as iniciativas em curso se reduziam, grande parte das vezes, a alterações que não chegavam efetivamente a colocar em questão os modelos de atenção e de gestão instituídos. Vale destacar que entre os anos 1999 e 2002, além do PNHAH, algumas outras ações e Programas foram propostos pelo Ministério da Saúde voltados para o que também ali ia se definindo como

${ }_{1}^{1}$ Professora, Departamento de Psicologia, Universidade Federal Fluminense, Niterói, RJ; coordenadora da Política Nacional de Humanização do Ministério da Saúde de jan. 2003 a jan. 2005. <rebenevi@terra.com.br>

2 Professor, Departamento de Psicologia, Universidade Federal Fluminense, Niterói, RJ; consultor da Política Nacional de Humanização do Ministério da Saúde de jul. 2003 a fev. 2005. <e.passos@superig.com.br>

${ }^{1}$ Departamento de Psicologia/UFF

Campus do Gragoatá, bloco O, $2^{\circ}$ andar

Gragoatá - Niterói, RJ

24.000-000 


\section{DEBATES}

campo da humanização contornado pelo debate sobre busca da qualidade na atenção ao usuário. Apenas para citar alguns, destacamos a instauração do procedimento de Carta ao Usuário (1999), Programa Nacional de Avaliação dos Serviços Hospitalares - PNASH (1999); Programa de Acreditação Hospitalar (2001); Programa Centros Colaboradores para a Qualidade e Assistência Hospitalar (2000); Programa de Modernização Gerencial dos Grandes Estabelecimentos de Saúde (1999); Programa de Humanização no PréNatal e Nascimento (2000); Norma de Atenção Humanizada de Recém-Nascido de Baixo Peso - Método Canguru (2000), dentre outros. Ainda que a palavra humanização não apareça em todos os Programas e ações e que haja diferentes intenções e focos entre eles, podemos acompanhar uma tênue relação que vai se estabelecendo entre humanização-qualidade na atenção-satisfação do usuário.

A humanização, expressa em ações fragmentadas e numa imprecisão e fragilidade do conceito, vê seus sentidos ligados ao voluntarismo, ao assistencialismo, ao paternalismo ou mesmo ao tecnicismo de um gerenciamento sustentado na racionalidade administrativa e na qualidade total. Para ganhar a força necessária que dê direção a um processo de mudança que possa responder a justos anseios dos usuários e trabalhadores da saúde, a humanização impõe o enfrentamento de dois desafios: conceitual e metodológico.

\section{Desafio conceitual}

Não podemos retomar o conceito de humanização sem considerar o cenário no qual ele vem ganhando destaque crescente em Programas no campo da saúde pública. Tal concentração temática indica o que poderíamos chamar de um modismo que, enquanto tal, padroniza as ações e repete modos de funcionar de forma sintomática. Neste sentido, é possível afirmar que a humanização ganha, no início dos anos 2000, um aspecto de conceito-sintoma.

Estamos chamando de conceito-sintoma a noção que paralisa e reproduz um sentido já dado. É como tal que o tema da humanização se reproduziu em seus sentidos mais estabilizados ou instituídos, perdendo, assim, o movimento pela mudança das práticas de saúde do qual esta noção adveio, movimento que se confunde com o próprio processo de criação do SUS nos anos 1970 e 1980. Sabemos, por outro lado, que a luta pela humanização das práticas de saúde já estava colocada na pauta do movimento feminista na década de 1960, ganhando expressão no debate em torno da saúde da mulher (Carnot, 2005; Costa, 2004; Vieira, 2002; Almeida, 1984). Dos anos 1960 aos 1980, podemos, então, acompanhar o movimento instituinte pela mudança das práticas de saúde. Este movimento chega aos anos 2000 encontrando ou se chocando com o que, paradoxalmente, dele resulta: formas instituídas, marcas ou imagens vazias, slogans já sem a força do movimento instituinte. É assim que a humanização se apresenta como um conceito-sintoma presente em práticas de atenção: a) segmentadas por áreas (saúde da mulher, saúde da criança, saúde do idoso) e por níveis de atenção (assistência hospitalar); b) identificadas ao exercício de certas profissões (assistente social, psicólogo) e a características de gênero (mulher); c) orientadas por exigências de mercado que devem "focar o cliente" e "garantir qualidade total nos serviços".

Apontar este caráter sintomático do conceito de humanização impõe que, ao mesmo tempo, identifiquemos o que aí se paralisa, mas também aquilo que insiste como índice de um movimento que não se esgota, sua face positiva. Colocar em análise o conceitosintoma é permitir a retomada de um processo pelo qual se faz a crítica ao que se instituiu nas práticas de saúde como o "bom humano", figura ideal que regularia as experiências concretas.

A necessidade de recolocação do problema da humanização obriga-nos, então, a forçar os limites do conceito resistindo a seu sentido instituído. Contra uma idealização do humano, o desafio posto é o de redefinir o conceito de humanização a partir de um

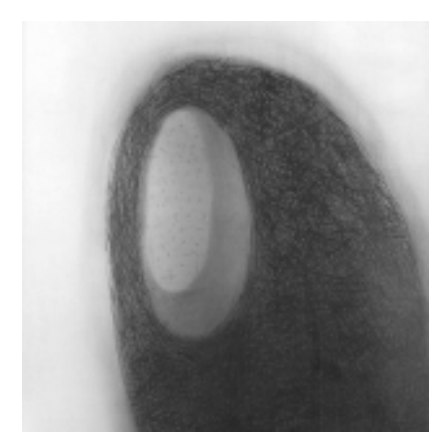


${ }^{3} \mathrm{Na}$ XII CNS a PNH fez sua primeira apresentação nacional. $\mathrm{Na}$ ocasião, foi feito um registro das imagens do estande HumanizaSus onde os delegados davam depoimentos acerca de experiências de humanização da saúde em seus municípios. Essas imagens foram editadas no video "PNH na XII CNS" (2004) em que as falas dos delegados apareciam sob o emblema "O SUS que dá certo". "reencantamento do concreto" (Varela, 2003) ou do "SUS que dá certo"3. Esta crítica ao Homem como figura-ideal desencarnada e ao seu sobrevôo regulatório, longe de abandonar todo e qualquer princípio de orientação, coloca em questão as práticas normalizadoras apostando, em contraste, na "normatividade" do vivo como capacidade menos de seguir do que de criar normas (Canguilhem, 1978). É neste sentido que a humanização não pode ser pensada a partir de uma concepção estatística ou de distribuição da população em torno de um ponto de concentração normal (moda). O que queremos defender é que o humano não pode ser buscado ali onde se define a maior incidência dos casos ou onde a curva normal atinge sua cúspide: o homem normal ou o homem-figura-ideal, metro-padrão que não coincide com nenhuma existência concreta.

Partir das existências concretas é ter de considerar o humano em sua diversidade normativa e nas mudanças que experimenta nos movimentos coletivos. Tal desidealização do Homem (Benevides \& Passos, 2005) dá como direção o necessário reposicionamento dos sujeitos implicados nas práticas de saúde. Assim, redefinindo o conceito, tomamos a humanização como estratégia de interferência nestas práticas levando em conta que sujeitos sociais, atores concretos e engajados em práticas locais, quando mobilizados, são capazes de, coletivamente, transformar realidades transformando-se a si próprios neste mesmo processo. Trata-se, então, de investir, a partir desta concepção de humano, na produção de outras formas de interação entre os sujeitos que constituem os sistemas de saúde, deles usufruem e neles se transformam, acolhendo tais atores e fomentando seu protagonismo.

Mas a redefinição do conceito de humanização deve ganhar outra amplitude quando estamos implicados na construção de políticas públicas de saúde. Afinal, de que nos serve este esforço conceitual se isso não resultar em alteração nas práticas concretas dos serviços de saúde, na melhoria da qualidade de vida dos usuários e na melhora das condições de trabalho dos profissionais de saúde? Neste sentido, impõe-se um outro desafio, o da alteração dos modos de fazer, de trabalhar, de produzir no campo da saúde.

\section{Desafio metodológico}

Quando falamos de modos de fazer estamos às voltas com o processo de construção de uma política pública que não pode se manter apenas como propostas, Programas, portarias ministeriais. Da política de governo à política pública não há uma passagem fácil e garantida. Construir políticas públicas na máquina do Estado exige todo um trabalho de conexão com as forças do coletivo, com os movimentos sociais, com as práticas concretas no cotidiano dos serviços de saúde (Benevides \& Passos, 2005). Neste sentido, a Política de Humanização só se efetiva uma vez que consiga sintonizar "o que fazer" com o "como fazer", o conceito com a prática, o conhecimento com a transformação da realidade. Os termos postos aqui em contraste não podem ser entendidos como opostos, mas ligados numa relação de pressuposição recíproca. Se teoria e prática se distinguem, mas não se separam, somos levados, então, a inverter uma afirmação do senso comum de que conhecemos, teorizamos, definimos conceitos para em seguida aplicá-los a uma realidade. Seguindo a indicação institucionalista (Lourau et al., 1977a; 1977b) é preciso transformar a realidade para conhecê-la. E de que realidade estamos falando? Aquela das práticas de saúde e, mais especificamente, das práticas de construção de políticas de saúde com que estamos envolvidos ao afirmar a importância do debate em torno da humanização.

Transformar os modos de construir as políticas públicas de saúde impõe o enfrentamento de um modus operandi fragmentado e fragmentador, marcado pela lógica do especialismo e do que se supõe como especificidade da humanização em determinadas áreas. Entretanto, fazer este movimento de mudança da lógica da racionalidade técnico-burocrática nas práticas de saúde e de compartimentalização/ individualização taylorista dos processos de trabalho, sempre poderá incorrer no risco da 


\section{DEBATES}

defesa de um sentido de humanização tão amplo que acabaria por se confundir com o que é princípio do SUS. Tal perigo é apontado por críticos da humanização que a entendem como apenas repetindo o princípio da integralidade. De fato, o princípio da integralidade é um anseio que o SUS elege como uma das direções-norte do sistema de saúde. Assim, não caberia mesmo pensar numa "política da integralidade" como afirma Ruben Mattos em entrevista à RET-SUS (Fiocruz, 2005). Uma política não pode se confundir com um princípio e a humanização como política pública de saúde deve estar efetivando, no concreto das práticas de saúde, os diferentes princípios do SUS. Uma política se orienta por princípios, mas está comprometida também com modos de fazer, com processos efetivos de transformação e criação de realidade.

Se a humanização não pode ser tomada como um princípio, mas se propõe como política, é porque sua efetividade não se faz enquanto proposta geral e abstrata. No entanto, não basta defender o caráter específico e concreto das práticas de humanização, pois tomá-las em sua especificidade pode incorrer no risco de repetir a tendência a compartimentalização e isolamento das ações como, por exemplo, a separação entre a humanização do parto e a humanização das emergências. Daí a difícil questão: qual o sentido de uma política de humanização que não se confunda com um princípio do SUS, o que a tornaria ampla e genérica, nem abstrata porque fora das singularidades da experiência, nem que aceite a compartimentalização, mas que se afirme como política comum e concreta nas práticas de saúde?

O SUS é uma conquista que se expressa, sem dúvida, como proposição geral e abstrata na forma do texto da lei, das portarias e normativas. No entanto, o projeto ele mesmo do SUS não pode suportar uma existência descolada do plano das experiências concretas no qual o movimento instituinte da Reforma Sanitária fez valer a aposta em mudanças nas práticas de saúde. É a idéia de "único", encontrada no SUS, que indica o tipo de projeto e, sobretudo, a forma de sua implantação no socius. Um Sistema de saúde para ser único precisa implantar-se como um plano comum que conecta diferentes atores no processo de produção de saúde. É neste sentido que os princípios do SUS não se sustentam numa mera abstração, só se efetivando por meio da mudança das práticas concretas de saúde.

Mas como garantir esta implantação? Realizar mudanças dos processos de produção de saúde exige também mudanças nos processos de subjetivação, isto é, os princípios do SUS só se encarnam na experiência concreta a partir de sujeitos concretos que se transformam em sintonia com a transformação das próprias práticas de saúde. Apostar numa Política Nacional de Humanização do SUS é definir a humanização como a valorização dos processos de mudança dos sujeitos na produção de saúde. Há, portanto, uma inseparabilidade entre estes dois processos, o que faz da humanização um catalisador dos movimentos instituintes que insistem no SUS.

Devemos, ainda, desdobrar a pergunta anterior argüindo o que estamos designando como processos de mudança subjetiva. Como realizar estas mudanças? A humanização enquanto política de saúde se constrói com as direções da inseparabilidade entre atenção e gestão e da transversalidade. Tais direções indicam o "como fazer" desta política que se concretiza como "tecnologias relacionais". É a partir da transformação dos modos de os sujeitos entrarem em relação, formando coletivos, que as práticas de saúde podem efetivamente ser alteradas.

Mudamos as relações no campo da saúde quando, por um lado, experimentamos a inseparabilidade entre as práticas de cuidado e de gestão do cuidado. Cuidar e gerir os processos de trabalho em saúde compõem, na verdade, uma só realidade, de tal forma que não há como mudar os modos de atender a população num Serviço de saúde sem que se alterem também a organização dos processos de trabalho, a dinâmica de interação da equipe, os mecanismos de planejamento, de decisão, de avaliação e de participação. Para tanto são necessários arranjos e dispositivos que interfiram nas 


\section{DEBATES}

formas de relacionamento nos serviços e nas outras esferas do sistema, garantindo práticas de co-responsabilização, de co-gestão, de grupalização (Campos, 2000).

Por outro lado, não há como mudar as formas de relacionamento nas práticas de saúde sem que aumentemos os graus de comunicação, de conectividade e de intercessão (Deleuze, 1992) intra e intergrupos nos serviços e nas outras esferas do sistema. Chamamos de transversalidade (Guattari,1981) o grau de abertura que garante às práticas de saúde a possibilidade de diferenciação ou invenção, a partir de uma tomada de posição

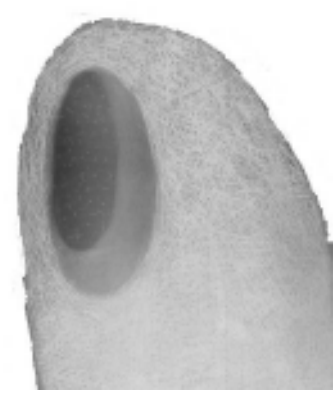
que faz dos vários atores sujeitos do processo de produção da realidade em que estão implicados. Aumentar os graus de transversalidade é superar a organização do campo assentada em códigos de comunicação e de trocas circulantes nos eixos da verticalidade e horizontalidade: um eixo vertical que hierarquiza os gestores, trabalhadores e usuários e um eixo horizontal que cria comunicações por estames. Ampliar o grau de transversalidade é produzir uma comunicação multivetorializada construída na intercessão dos eixos vertical e horizontal.

Na qualificação do SUS, a humanização não pode ser entendida como apenas mais um Programa a ser aplicado aos diversos serviços de saúde, mas como uma política que opere transversalmente em toda a rede SUS. O risco de tomarmos a humanização como mais um Programa seria o de aprofundar relações verticais em que são estabelecidas normativas que devem ser aplicadas e operacionalizadas, o que significa, grande parte das vezes, efetuação burocrática, descontextualizada e dispersiva, por meio de ações pautadas em índices a serem cumpridos e metas a serem alcançadas independentes de sua resolutividade e qualidade.

Com isto, estamos nos referindo à necessidade de adotar a humanização como política transversal que atualiza um conjunto de princípios e diretrizes por meio de ações e modos de agir nos diversos serviços, práticas de saúde e instâncias do sistema, caracterizando uma construção coletiva. A humanização como política transversal supõe necessariamente ultrapassar as fronteiras, muitas vezes rígidas, dos diferentes núcleos de saber/poder que se ocupam da produção da saúde. Entendemos, entretanto, que tal situação de transversalidade não deve significar um ficar fora, ou ao lado, do SUS. A humanização deve caminhar, cada vez mais, para se constituir como vertente orgânica do Sistema Único de Saúde fomentando um processo contínuo de contratação, de pactuação que só se efetiva a partir do aquecimento das redes e fortalecimento dos coletivos (Passos \& Benevides, 2004). Mas, sua afirmação como política transversal deve garantir o caráter questionador das verticalidades pelas quais estamos, na saúde, sempre em risco de nos ver capturados.

O confronto de idéias, o planejamento, os mecanismos de decisão, as estratégias de implementação e de avaliação, mas principalmente o modo como tais processos se dão, devem confluir na construção de trocas solidárias e comprometidas com a produção de saúde, tarefa primeira da qual não podemos nos furtar. De fato, a tarefa se apresenta dupla e inequívoca: produção de saúde e produção de sujeitos. Construir tal política impõe, mais do que nunca, que o SUS seja tomado em sua perspectiva de rede, criando e/ou fortalecendo mecanismos de coletivização e pactuação sempre orientados pelo direito à saúde que o SUS na constituição brasileira consolidou como conquista. É no coletivo da rede SUS que novas subjetividades emergem engajadas em práticas de saúde construídas e pactuadas coletivamente, reinventando os modelos de atenção e de gestão.

Se partimos da crítica ao conceito-sintoma, concluímos afirmando a humanização como um conceito-experiência que, ao mesmo tempo, descreve, intervem e produz a realidade nos convocando para mantermos vivo o movimento a partir do qual o SUS se consolida como política pública, política de todos, política para qualquer um, política comum. 


\section{DEBATES}

\section{Referências}

ALMEIDA, M. F. Planejamento familiar: seis razões para ser contra. Saúde em debate, n.15/16, 1984.

BENEVIDES, R.; PASSOS, E. A humanização como dimensão pública das políticas de saúde. Ciência \& Saúde Coletiva, v.10, n.3, 2005. (no prelo).

CAMPOS, G. W. S. Um método para análise e co-gestão de coletivos: a construção do sujeito, a produção de valor de uso e a democracia em instituições: o método da roda. São Paulo: Hucitec, 2000.

CARNOT, E. Humanização e políticas de saúde: um estudo sobre os usos e sentidos das propostas de humanização nas políticas de atenção à saúde da mulher. 2005. Tese (Doutorado) Programa de Pós-Graduação em Saúde Coletiva, Instituto de Medicina Social, Universidade do Estado do Rio de Janeiro, Rio de Janeiro.

COSTA, A. M. Atenção integral à saúde das mulheres: quo vadis? uma avaliação da integralidade na atenção à saúde das mulheres no Brasil. 2004. Tese (Doutorado) - Programa de Pós-Graduação em Ciências da Saúde, Faculdade de Ciências da Saúde, Universidade de Brasília, Brasília.

CANGUILHEM, G. O normal e o patológico. Rio de Janeiro: Forense Universitária, 1978.

DELEUZE, G. Os intercessores. In: DELEUZE, G. Conversações. Rio de Janeiro: Editora 34, 1992. p.151-68.

FIOCRUZ. Humanização da saúde: o homem como "medida de todas as coisas". Revista RET-SUS, v.1, n.6, p.4-7, 2005

GUATTARI, F. Transversalidade. In: GUATTARI, F. Revolução molecular: pulsações políticas do desejo. São Paulo: Brasiliense, 1981. p.88-105.

LOURAU, R. LAPASSADE, G.; HESS, R.; SAVOYE, A.; GAVARINI, L.; VILLE, P.; BRUCE, P.; COSSON, P. G.; EVRARD, P. Análisis institucional y socioanálisis. México: Editorial Nueva Imagen, 1977a.

LOURAU, R.; LAPASSADE, G.; AUTHIER, M.; SAVOYE, A.; HESS, R.; GUIGOU, J.; BOTERF, G.;

GUATTARI, F.; BERNARD, M.; LOBROT, M. El análisis institucional. Madri: Campo Abierto,1977b.

PASSOS, E.; BENEVIDES, R. Clinica, política e as modulações do capitalismo. Lugar Comum, n.19-20,

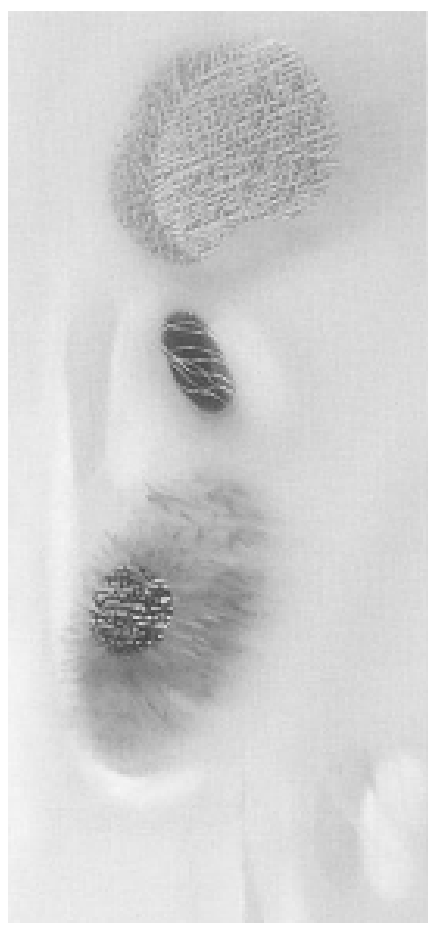

p.159-71, 2004.

VARELA, F. O reencantamento do concreto. In: PELBART, P. P.;

COSTA, R. (Org.) Cadernos de subjetividade: o reencantamento do concreto. São Paulo: Hucitec, 2003. p.33-52.

VIEIRA, E. M. A medicalização do corpo feminino. Rio de Janeiro: Fiocruz, 2002.

Recebido para publicação em: 23/05/05. Aprovado para publicação em: 28/05/05. 